\title{
A Brief Review of Briony in Each Period in the Atonement from the Perspective of Sigmund Freud's Psychoanalysis
}

\author{
Jiaojiao Liu \\ East China University of Science and Technology, Shanghai, China \\ Email: 18838982131@163.com
}

How to cite this paper: Liu, J.J. (2020) A Brief Review of Briony in Each Period in the Atonement from the Perspective of Sigmund Freud's Psychoanalysis. Open Access Library Journal, 7: e6889.

https://doi.org/10.4236/oalib.1106889

Received: October 9, 2020

Accepted: October 24, 2020

Published: October 27, 2020

Copyright $\odot 2020$ by author(s) and Open Access Library Inc.

This work is licensed under the Creative Commons Attribution International License (CC BY 4.0).

http://creativecommons.org/licenses/by/4.0/

\section{(c) (i) Open Access}

\begin{abstract}
The works of Ian McEwan are mostly related to violence and ethics, which once brought him the nickname Ian Macabre. Atonement is the ninth work of McEwan. It unfolds through Briony's sin and atonement. This paper is a brief review of Briony in different periods in the Atonement from the perspective of Sigmund Freud's Psychoanalysis. It aims to interpret Briony's image from Freud's Ego, Id and Superego. To provide reader a new understanding of this novel.
\end{abstract}

\section{Subject Areas}

Linguistics, Literature

Keywords

Ian McEwan, Briony, Freud's Psychoanalysis, Sin and Atonement

\section{1. 引言}

伊恩・麦克尤恩的作品非常擅长人物心理刻画, 侧重于描写人物内心世 界的变化。其早期作品的题材涉猎广泛，包含诸如暴力、伦理和畸恋等一些 偏阴暗的话题。除此之外, 他的作品也非常大胆, 敢于刻画和揭露人内心最 深的欲望和幻想, 文笔锐利, 才华横溢。因其独特的写作风格和视角, 麦克 无恩的很多作品都受到英国文坛和广大读者的欢迎，同时也让他获得了 “恐 怖伊恩” 的称号，而且英国评论家称之为英国的 “国民小说家”。

《赎罪》的写作风格和技巧十分独特, 不管是人物心理刻画, 还是有关 于人性和道德观的刻画都十分成功。历史上重大事件只是个人生活的潜在背 景, 或者说是构成主人公命运的坎坷和心理创伤的一个隐喻 $[1]$ 。《赎罪》故 
事背景设定在作者没有经历过的第二次世界大战前后。主要围绕年仅 13 岁， 沉迷于文学世界, 充满幻想的女主人公布里奥妮展开叙述。她年幼无知与自 私, 错误地指证了其家里佣人的儿子罗比是强奸犯, 害得罗比锒铛入狱。最 终改变了无享少年的一生, 间接地害了罗比, 致其在战争中丧生。不仅如此, 也害了她的姐姐塞西莉亚, 害得一对有情人无法相爱相守, 最终双双丧生。 成年之后的布里奥妮逐渐意识到了自己的错误, 穷其一生在无尽的忓悔与自 责中度过。这部小说创作至今, 引发了许多讨论, 以陌生化技巧的运用、以 及小说中的伦理关怀和元小说等角度的讨论居多。本文从弗洛伊德的人格结 构理论出发, 主要对不同时期布里奥妮的心理特征进行解读, 从一个新的视 角来认识布里奥妮和《赎罪》这部小说。

\section{2. 弗洛伊德人格结构理论}

根据弗洛伊德的人格结构理论, 人格作为一种心理机制, 它是从内部控 制人的外在行为的。而且, 一个人在一切给定情境中的行为特征或行为模式 都将由这种内部心理机制决定。据此, 他提出了完整的人格结构理论, 主要 包括三大部分, 即, “本我”、“自我” 和 “超我”。

\section{1. 本我(Id)}

弗洛伊德明确指出人格结构的最基本层次是 “本我” “ “本我” 指向一 切本能的驱动力, 执着于眼前的满足, 急切的追求本能和欲望。 “本我” 的 冲动, 始终是一种无意识的冲动。它处于内心最深处, 属 “无意识” 层。

\section{2. 自我(Ego)}

“自我”处于人格结构中间一层。“自我” 是 “本我” 和 “超我”之间 的媒介。指向理性和机智, 发挥着防卫和中介职能。它充当仲裁者, 规范 “本 我” 的行为和欲望。它能决定自己行为方式的意识。通常根据周围环境的实 际条件调节 “本我” 和 “超我” 的矛盾, 来达到理性或正确的判断。

\section{3. 超我(Superego)}

根据人格三层结构, “超我” 位于最上层, 能进行自我批判以及道德控 制。是一种理想化的 “自我”。作为最高级的 “超我” 代表良心、社会准则 和自我理想。“超我” 践行至善原则, 引导 “自我” , 约束 “本我”。

\section{3. 布里奥妮不同时期的心理特征}

《赎罪》共分为四个章节。在第一部分描述了故事的开端, 13 岁的布里 奥妮因自己的无知和自私导致无幸少年罗比蒙冤入狱; 第二部分, 描写战争 的残酷, 罗比饱受战争的考验和摧残; 第三部分, 罗比因为蒙冤入狱, 人生 轨迹突变。出狱后的他虽然身体获得了自由, 但是心理和精神上发生了很大 的变化。为了重获精神的 “自由”, 冲刷过去所遭受到的耻辱, 与塞西莉娅 “自由” 的在一起, 而从军。然而造化弄人, 罗比在战争中死去, 姐姐也因 事故身亡。这一部分侧重于布里奥妮成年之后, 逐渐意识到自己的过错, 无 
比后悔。希望通过做护工, 以求得内心的平静和赎罪。第四部分中, 真正犯 错的人不仅没有受到惩罚, 反而成为了受人敬仰的公众人物。马歇尔夫妇的 一生顺风顺水, 真正有罪的人逍遥法外, 无鼓的少年, 相爱的两人最终惨死, 老年的布里奥妮在忓悔的一生中度过。她希望最终能通过小说将事实在自己 死后公布于世人, 将真正的过错之人揭露出来, 为自己赎罪。本文从弗洛伊 德人格结构理论视角分析, 主要从 “自我” “ “本我” 和 “超我” 角度, 深 入探究《赎罪》中布里奥妮不同时期的心理特征, 对其人物形象进行更深层 次的解读。

\section{1. 少女时期的无知和自私}

根据弗洛伊德给出的定义, “本我” 是一种与生俱来的, 受到动物性的 本能支配的原始冲动。在这一阶段, 布里奥妮的行为主要受到无意识的 “本 我” 的影响。在小说《赎罪》中, 13 岁的布里奥妮喜欢写作, 充满了文学性 的幻想, 因为缺乏对于成人世界的认知, 而犯下了一生无法弥补的错误。因 为无意间在窗帘之后目睹了水池边发生的一幕, 她便认为罗比, 傲慢无礼, 强迫了自己的姐姐塞西莉娅。紧接着罗比误将错误的信给了布里奥妮, 让布 里奥妮代为转交给塞西莉娅。文中 “他向她挥了挥手, 他朝她走过去, 她点 头接过信封, 突然他的脑海里闪现一个不安的观念” [2]。布里奥妮是一个对 秘密有着极大好奇心的人。为了满足自己的好奇心, 布里奥妮在将信转交给 姐姐之前, 偷偷拆了信, 而信中罗比无意写下的那些不堪入目的字眼, 在布 里奥妮眼中无疑是对姐姐塞西莉娅极大的冒犯。布里奥妮对罗比的误会更深 一步, 紧接着在晚餐前, 布里奥妮无意间闯入书房, 所看到的一幕: 罗比与 姐姐塞西莉娅交缠在一起的身影。布里奥妮断定罗比强迫了姐姐。尤其在晚 上当发现表姐罗拉被人强暴之后, 布里奥妮下意识的问罗拉: “是他, 对不 对?” [3] 可见在布里奥妮的潜意识里已经将罗比认定为一个强奸犯了。

根据弗洛伊德的人格结构理论来看, 此时的布里奥妮尚且年幼, 阅历不 足, 对于客观世界缺少足够的认知。主要受到 “本我” 的支配, 追求欲望和 本能的满足。布里奥妮是一个沉浸在自己世界中、充满文学幻想的少女。13 岁的她无法理性思考, 未形成规范的道德标准和逻辑推理。在小说中幼年时 期布里奥妮与罗比之间的 “游泳事件” : 布里奥妮问罗比, 如果自己掉进河 里, 他会不会救自己, 在得到罗比肯定的回答之后。布里奥妮故意跳进河里, 为的只是试探罗比会不会真的救自己, 并且在最后获救之后大胆的向罗比表 达爱意: “你知道为什么我要你救我吗? 因为我爱你” [3]。然而罗比并没有将 这个小女孩口中的话当真。年少的她慢慢将这份喜欢掩藏在心里, 而根据弗 洛伊德的心理分析来看, 她的这份喜欢只是转化成了一种无意识的状态, 但 是并没有消失。尤其在发现罗比与姐姐塞西莉娅之间可能存在某种难言的情 愫之时, 布里奥妮的 “本我” 意识, 便不受约束和控制, 以一种毁灭性的姿 态冲撞开来。

而另一方面来讲, 布里奥妮又是一个充满自我矛盾的人, 她充满幺想, 却又对秩序无尽向往。她认为一切事物都必须充满秩序, 她对秩序所持有的 这种执念。从她房间的井然有序, 以及人偶模型的排列等都可以看出来。在 
一定程度上, 她对秩序的这种狂热, 是受到了 “超我” 的支配的。一方面 “本 我” 的欲望让她充满了幻想和渴望, 和对与罗比之间的爱情的向往。另一方 面, “超我” 的规范性行为, 是一种理想化了的 “自我”。年幼的布里奥妮 对于秩序的追求近乎痴迷, 同时也制约了布里奥妮对于罗比的感情。处于 “本 我” 和 “超我” 的两种矛盾之中, 充当仲裁者的 “自我” 便开始发挥其职能。 作为二者的调节中介, 在目睹喷泉旁边发生的一切、罗比写给姐姐的不堪信 件、书房罗比与塞西莉娅交缠的身影, 再到表姐罗拉遭强暴等一系列事情之 后，布里奥妮的 “自我” 意识不断膨胀。她以一种美其名曰主持公道、保护 姐姐、不让姐姐受到伤害、正义之举等自我麻痹的说法, 指认罗比就是强奸 犯。由此可见, 此时布里奥妮的心理变化主要还是受到了 “本我” 欲望的支 配, 她依托于 “自我” , 为自己少女时期的无知与自私找到了借口 “非要揭 开他虚伪的面纱”、“哪怕塞西莉娅没有任何感激的表示”, 正是她这种自 以为是的自私行为最终导致姐姐与罗比两个无比相爱的人悲惨的一生。

总的来说, 在这一阶段中布里奥妮内心对于一切秘密的好奇心; 对充满 秩序的世界的追求; 对于文学化了的爱情的向往等一系列的心理变化无不影 响着这个十三岁少女的行动。对于秘密的好奇心, 驱使着布里奥妮打开了罗 比写给姐姐的表白信。对于秩序世界的追求, 使得布里奥妮的房间有别于姐 姐的错乱, 身为妹妹的她房间反而更加整洁, 井然有序。除此之外, 对于爱 情盲目幻想以及长期沉浸在自己的文学幻想中缺乏对现实世界的认知和沟 通, 使得她十分盲目, 甚至自以为是的相信自己的判断。弗洛伊德曾指出, “本我” 诱使 “自我” 满足它的欲望, “超我”约束 “自我” 压抑 “本我” 的欲望 [4]。包括她在断定罗比就是强奸表姐的凶手前内心的一番推理活动, 也是充满了文学性和戏剧化的。由此可见, 个人的心理活动和心理变化, 对 于个人的行为有着驱使和指向的作用。

\section{2. 成年时期的矛盾与后悔}

许多年后, 经过战事长大了的布里奥尼再次见到罗比夫妇的时候, 面对 罗比的质问, 她无法回答, 只是支吾的辩护, “我正在长大” [4]。在这一阶 段中, 布里奥妮一直在寻求心灵的救赎, “自我” 意识开始规范 “本我” 意 识。成年以后的布里奥妮, 在认知上有所成长, 最终意识到了自己的过错。 她一直处于一种内疚自责的情绪之中, 放弃去剑桥求学。为了减轻自己内心 的痛苦和折磨, 布里奥妮在战地医院做当了一名普通护士。她终日通过写作 和工作麻痹自己。但是, 这并没有让她的痛苦减轻多少, 她试图写信给姐姐 乞求原谅, 也并没有得到姐姐的回信。

弗洛伊德认为, 人的健康全面发展, 依赖于三个 “我” 和谐共处。因此, 当三者产生分歧, 人有时会陷入矛盾和自我怀疑的情绪中。它主要包括两个 方面:一方面是平常人们所说的 “良心”, 代表着社会道德对个人的惩罚和规 范作用; 另一方面是 “理想自我” , 确定道德行为的标准 [3]。布里奥妮的自 我意识和自我救赎在医院展示得淋漓尽致。通过写作和照顾病人来宽慰自己, 希望得到罗比和姐姐的原谅。“只有在日记和写作中, 她才可以得到一丝慰 藉” [5]。此时的布里奥妮虽然逐渐成熟, 但是根据弗洛伊德的人格理论分析 
来看, 她的懦弱仍然让她没有勇气将事实真相公布与众。在这一阶段上, “本 我” 是造成她这一行为的主要驱动力量。她唯有通过不断的写作, 来宽慰自 己。就在她鼓起勇气要将真相公之于众的时候, 此时, 根据弗洛伊德的精神 分析理论来看, 布里奥妮的 “超我” 意识或许占据了上风, 她大义凛然决心 为自己赎罪, 敢于面临由此带来的一系列后果。但是造化弄人, 当年强暴了 表姐的强奸犯马歇尔竟然要和表姐罗拉举行婚礼。她目睹二人走进了婚姻的 殿堂, 懦弱和无力让她开不了口说出任何反对的话。此时, 布里奥妮的 “本 我” 意识, 即内心最深处的恐惧和懦弱影响了 “自我” 意识的决策, 她终究 无法将事实公布出来。最终姐姐与罗比双双丧生, 布里奥妮永远无法得到姐 姐和罗比亲口的原谅。

\section{3. 老年时期的反省与忓悔}

老年时期的布里奥妮, 在悔恨与忓悔中度过了一生。为了能得到内心的 宽慰, 为了给自己幼年的错误赎罪, 她借助于写作, 将事实真相公布出来, 而我们知道, 这也并非完全真实。然而, 现实中姐姐死于一起爆炸事故, 而 罗比也由于在战争中身患败血症慢慢死去。在小说的结尾姐姐塞西莉娅与罗 比二人重逢, 最终生活在了一起。在这一阶段也是布里奥妮 “自我” 意识最 为凸显的时期。“自我” 时常处于外部世界、“本我” 欲望和 “超我” 约束 之中, 就像是一个 “和事佬” ，努力调节三者之间的矛盾和冲突。文中的作 者兼主人公布里奥妮改写了结局, 以宽慰自己。这是她自我中前意识进一步 的突显, 也是元小说中一个鲜明的特征[6]。采用圆满的结尾方式, 让现实中 永远无法圆满的两个人，在小说的故事中能够永远生活在一起，由此也可见 布里奥妮对于这一事件深深的悔恨与愧疚。她内心的自责与忓悔无时无刻不 让自己备受煎謷, 致使她倾尽一生在赎罪中度过。年幼时候充满幻想和对秩 序的无尽向往，此时已经消失殆尽。布里奥妮用尽了一生的时间来为自己年 幼的错误赎罪, 然而永远无法获得真正的原谅, 也无法寻得内心的安宁。我 们不禁想到, 《赎罪》中真正该赎罪的人究竟是谁, 是布里奥妮一个人的错 误吗? 布里奥妮在成年后对自己的反省、对道德观的坚守都可以看出, 布里 奥妮并不是一个完全的坏人。然而, 真正的施暴者一一马歇尔夫妇逍遥法外, 甚至受人景仰， 《赎罪》不只是一个人的赎罪。

\section{4. 结论}

小说中布里奥妮 “自我”、“本我” 和 “超我”之间的矛盾十分突出。 由此我们也看到, 个人的心理活动和心理变化无时无刻不在影响着主体的行 动。或诱使主体 “误入歧途” 又或者为其指明 “正道”。对于 “本我” 和 “自 我” 的关系, 弗洛伊德有这样一个比喻: “本我” 是马, “自我” 是马车夫。 马是驱动力, 马车夫给马指方向。“自我” 要驾御 “本我” , 但马可能不听 话，二者就会僵持不下，直到一方屈服。“本我”、“自我”与 “超我” 三 者经常互相矛盾、斗争，特别是 “超我” 和 “本我” 经常处于不可调和的对 抗状态。个人心理活动对个人的行为有着很大的驱动作用。小说源于生活, 古往今来有许许多多有关于人性、道德和伦理的探讨, 无不让我们深思, 个 
人应当加强自己的道德约束, 不能放任心中 “本我” 的肆无忌惮。

\section{Conflicts of Interest}

The author declares no conflicts of interest regarding the publication of this paper.

\section{References}

[1] 张和龙. 战后英国小说 $[\mathrm{M}]$. 上海: 上海外语教育出版社, 2006.

[2] 戴志红. 《赎罪》中布里奥妮的“对话” [J]. 现代语文(学术综合版), 2017(7): 83-85.

[3] 伊恩·麦克尤恩. 赎罪 [M]. 郭国良, 译. 上海: 上海译文出版社, 2008: 184.

[4] Freud, S. (1922) A General Introduction to Psychoanalysis. Boni and Liveright, New York.

[5] 梁萌萌. 《赎罪》中布里奥妮. 塔利斯的精神分析 [J]. 文学界(理版), 2013(1): $220+222$.

[6] 戴志红. 用精神分析法解读《续罪》中布里奥妮的心理变化过程[]]. 现代语文(学 术综合版), 2017(1): 67-68.

\section{Appendix (Abstract and Keywords in Chinese)} 弗洛伊德人格结构理论视角下 《赎罪》中布里奥妮各时期的心理特征

摘要: 伊恩 - 麦克无恩因其作品多为关于暴力和伦理类的题材, 素有 “恐 怖伊恩” 之称。 《赎罪》围绕女主人公布里奥妮的犯罪、赎罪展开叙述。本 文从弗洛伊德人格结构理论视角出发, 分析《赎罪》中布里奥妮在不同时期 的心理特征, 由自我、本我和超我角度对布里奥妮的形象进行解读, 为读者 提供一个新的视角来理解这部小说。

关键词: 伊恩 - 麦克尤恩, 布里奥妮, 弗洛伊德人格结构理论, 犯罪和 赎罪 